Brit. F. industr. Med., 1968, 25, 304

\title{
Toxicity of Paraquat and Diquat Aerosols Generated by a Size-selective Cyclone: Effect of Particle Size Distribution
}

\author{
J. C. GAGE \\ From Imperial Chemical Industries Limited, Industrial Hygiene Research Laboratories, Alderley Park, \\ Macclesfield, Cheshire
}

The toxicity of paraquat and diquat aerosols to several species has been investigated. In order to obtain an atmosphere of 'respirable' particles, an atomizer has been constructed with an upper cut-off of size by a cyclone separator, and with a calibrated reservoir to enable the concentration output to be estimated by inspection.

Paraquat has an irritant action on the lungs, and at lethal concentrations death is delayed and is associated with pulmonary haemorrhage and oedema. After single exposures the $\mathrm{LC}_{50}$ appears to be a function of the duration and of the concentration; in the rat the lethal concentration-time product (CT) is about $6 \mu \mathrm{g} . / 1 . \mathrm{hr}$. Guinea-pigs and male mice are about as sensitive as rats. Female mice and rabbits are less sensitive. The dog can tolerate a CT product of $25 \mu \mathrm{g}$. $/ \mathrm{l}$. hr without ill-effects. The toxicity is a complex function of particle size. In the rat it appears that the most effective size is in the region of $3 \mu$, as larger particles do not reach the alveolar regions and finer particles are probably not retained there.

Repeated daily 6-hr exposures of rats to paraquat aerosols over a three-week period produce signs of lung irritation but no deaths at $0.4 \mu \mathrm{g}$./1., and the no-effect level is about $0 \cdot \mathrm{I} \mu \mathrm{g}$./litre.

Paraquat appears to be poorly absorbed from the lungs. After single exposures death is associated with a paraquat content of about $6 \mu \mathrm{g}$. in the lungs. Paraquat is subsequently cleared from the lung with a half-life of about $36 \mathrm{hr}$.

Diquat is much less irritant to the lungs than is paraquat; the no-effect levels on single and repeated exposure are at least five times larger.

It is concluded that paraquat and diquat do not present an inhalation hazard under normal conditions of application, but with paraquat under abnormal conditions it may be desirable to provide respiratory protection.

Oral and intraperitoneal administration of the herbicides, paraquat and diquat, to a variety of animal species has shown that their acute and subacute systemic toxicity is not high (Clark, McElligott, and Hurst, 1966; Clark and Hurst, 1968). A local irritant action was observed on exposed epithelial membranes, notably on the pharynx and gastro-intestinal tract, and was more marked with paraquat than with diquat. This property was found also to give rise to a lung irritant action after intratracheal injection in the rat; the toxicity was high by this route, with $\mathrm{LD}_{50}$ values about 0.5 and $5 \mathrm{mg}$. $/ \mathrm{kg}$. for paraquat and diquat respectively, and with pulmonary oedema as the cause of death (Clark, personal communication).

Received for publication February 21, 1968.
In order to assess the hazard which may arise during the agricultural application of paraquat and diquat formulations, an investigation has been undertaken into the effects of aerosols of these herbicides on experimental animals, with particular attention to the influence of particle size on toxicity.

\section{Experimental Methods}

Preparation of Aerosols Three types of atomizers were used for the preparation of aerosols in this investigation. For relatively coarse aerosols (Fig. I) a concentric air jet atomizer with a controlled fluid-feed (Gage, 1953) was used. This was located in an outer tube into which was led a stream of diluting air. The particle size produced by such an atomizer depends on the linear flow of air at the jet, and an annular air gap was selected to produce an aerosol of the required size range at a convenient air flow. 


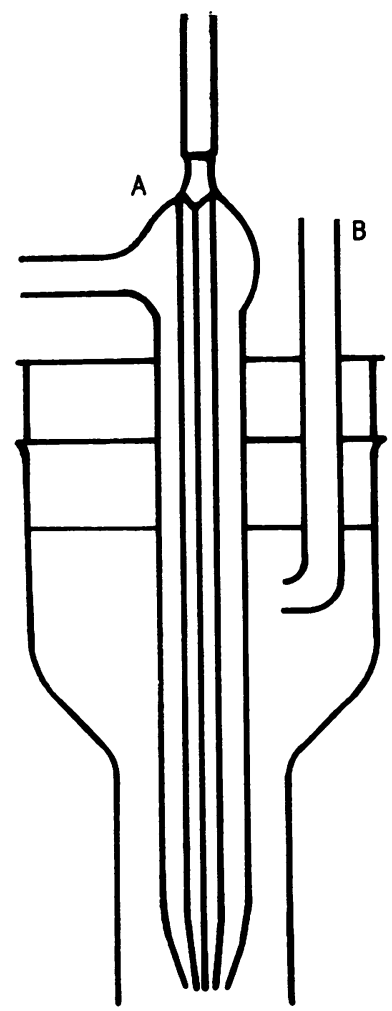

FIG. I. Atomizer for coarse aerosols. A, concentric jet atomizer; B, auxiliary air supply.
Particles sufficiently small to enter the lung alveoli ('respirable' particles) must be below about $5 \mu$ in diameter (Morrow, 1964; Hatch and Gross, 1964). Their preparation was achieved by the two assemblies shown in Fig. 2, one delivering vertically upwards (a) and one downwards $(b)$. The upper limitation of particle size was effected by means of a cyclone (A), $7.5 \mathrm{~cm}$. diameter and $1.5 \mathrm{~cm}$. deep at the periphery, shown in vertical section and in plan. The atomizer (B) was inserted tangentially, and the fine particles left by the central orifice (C), a B24 standard taper socket. The coarse particles impinged on the circumference of the cyclone and drained away into the tube (D) through which they returned to the liquid inlet of the atomizer. The delivery of the atomizer was controlled by the rate of air flow through (E) and the vertical height between the level of the liquid in (D) and the jet of the atomizer; this level was maintained by the constant level tube in the calibrated reservoir (F). The upper limit of the particle size range issuing from the cyclone was controlled by the flow of air and liquid through the atomizer, and by the shape of the cyclone. For the preparation of the aerosols, aqueous solutions of paraquat or diquat dichlorides of suitable concentration were used in the reservoir and the air supplied to the atomizer was saturated with water vapour. The total volume of particles leaving the cyclone in unit time could, therefore, be derived from the rate of fall of liquid in the reservoir. The mist leaving the cyclone was diluted with dry air at (G) to obtain an aerosol of solid crystals; the air flows were measured by means of rotameters calibrated at their working pressures, which enabled the concentration of paraquat in the atmosphere to be calculated. The relative humidity of the air in the chambers ranged between 30 and $50 \%$.

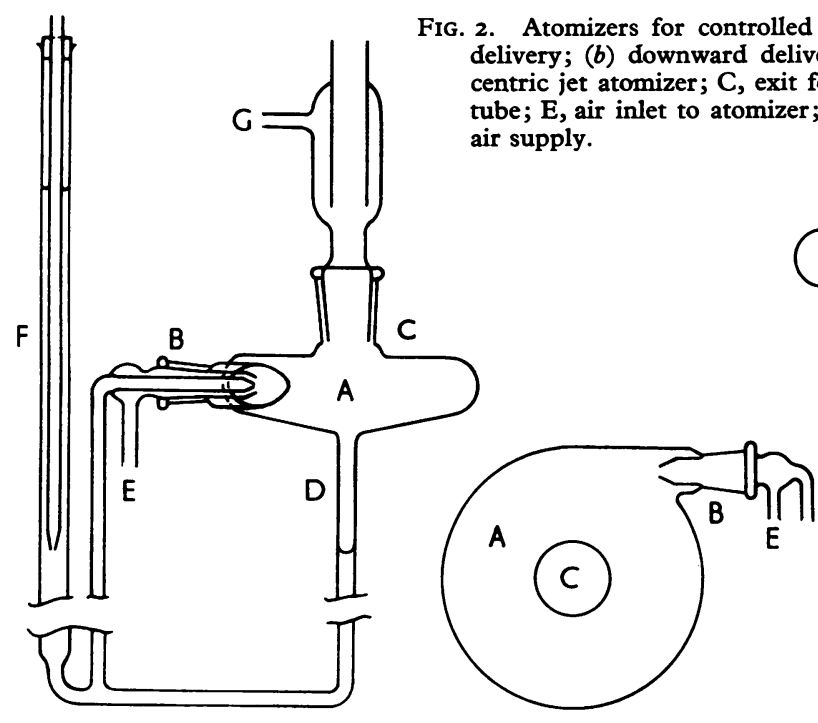

(a) 
Supplies of pure crystalline paraquat and diquat dichlorides were obtained from Plant Protection Ltd.

Analysis of Atmospheres The test atmospheres were sampled through a $2.5 \mathrm{~cm}$. diameter membrane filter $\mathrm{GM}_{4}$ (Gelman) at rates of up to ro $1 . / \mathrm{min}$., the volume of air sampled being adjusted to collect 20 to $50 \mu \mathrm{g}$. paraquat. The paper was extracted with $10 \mathrm{ml}$. water, and $2 \mathrm{ml} .0 .2 \mathrm{w} / \mathrm{v}$ sodium dithionite were added. For paraquat the dithionite was dissolved in N-sodium hydroxide, and for diquat in $5 \%$ aqueous sodium tetraborate. The colour developed was measured in I-cm. cells at $600 \mathrm{~m} \mu$ (paraquat) or at $379 \mathrm{~m} \mu$ (diquat). The amount of paraquat or diquat (ion) collected was determined from standard curves relating optical density to concentration. The efficiency of recovery from the filter was determined by adding a measured volume of standard paraquat or diquat solutions to the filter and allowing it to dry and then carrying out the determination. Recoveries approaching $100 \%$ were obtained.

The concentration of aerosol found by analysis in all experiments was less than that calculated from the consumption of solution and from the measured air flow. On average, the measured concentration was about $40 \%$ of the calculated, and was to some extent influenced by the concentration and particle size. The loss was presumably due to deposition of the particles on surfaces, although in all experiments the amounts deposited were too small to be visible. In the animal experiments described below, the concentrations of paraquat or diquat (ion) quoted are those obtained by analysis.

The size distribution of the aerosol particles was determined by a Unico Cascade Impactor (Lippmann, I96I). The glass microscope slides were coated with the grease described by Meloche and Fredrick (1932), and they were covered with adhesive cellulose tape to prevent contamination on the outside. At the end of the experiment the glass slide was broken in two, and each half was dropped into water to extract the paraquat, which was then determined as described above. The air sampling speed through the Cascade Impactor was adjusted so that the size ranges were suitable for the aerosol under investigation. The particle size range was derived from the nomogram published by Lippmann (I96I). The density of the solid dichlorides was taken to be $I \cdot 25$. The size distributions used in the various experiments are shown in Table I; these are expressed as mass median diameters of aerodynamically equivalent spheres of unit density.

Design of the Exposure Chambers For Expts. I, $3,7,8,9$, and II (see below) an exposure chamber similar to that previously described (Gage, 1959) was used. The atomizer (Fig. 2a) delivered up the central column.

A smaller chamber was designed for the shorter exposure periods in Expts. 2 and 6 . This is shown in Fig. 3; it was constructed from two 8-in. polyethylene funnels clamped together at the rim. A circular stainless-steel grid was fastened in the lower funnel to support the animal, and the aperture of this grid and the hole at the base of the funnel were made sufficiently large to permit passage of the excreta. A hole was cut at the apex of the upper funnel for insertion of the atomizer (Fig. 2b), and another hole was cut in the side of this funnel to take the sampling filter-holder.

A chamber of the design used for Expt. I could not be satisfactorily scaled up in size for the larger capacity required for Expts. 4 and Io. In order to obtain a proper distribution of the aerosol, it was necessary to construct a chamber with a pyramidal top and to inject the aerosol at the apex. The design is shown in Fig. 4; the chamber was constructed of Perspex and housed in an outer casing under exhaust ventilation. The outlet tube of the atomizer (Fig. 2b) passed through rubber stoppers in both the outer casing and the apex of the chamber, to make airtight seals with both. The same chamber, together with the atomizer shown in Fig. I, was used for the coarse aerosol in Expt. 5.

Experimental Animals Rats, mice, and guineapigs were of the Alderley Park SPF strain. The body weight of the rats in the single exposures was approximately $200 \mathrm{~g}$., and in the repeated exposures $160-180 \mathrm{~g}$. Mice were 25-30 g. and guinea-pigs about $500 \mathrm{~g}$. Rabbits (4 kg.) were a cross between New Zealand White and Californian White, and beagles (9-13 kg.) were from the Alderley Park kennels.

TABLE I

Particle Size Distribution of Aerosols (Weight \% in Size Ranges indicated by mass median diameter)

\begin{tabular}{|c|c|c|c|c|c|c|c|c|c|c|c|}
\hline & \multicolumn{11}{|c|}{ Experiment } \\
\hline & $I$ & 2 & 3 & 4 & 5 & 6 & 7 & 8 & 9 & IO & $I I$ \\
\hline$>$ Io $\mu$ & $I \cdot 2$ & 0.3 & I. 4 & $1 \cdot 7$ & $56 \cdot 0$ & 0.2 & $I \cdot O$ & 0.8 & 0.9 & $1 \cdot 5$ & $1 \cdot 4$ \\
\hline I0 $\mu$ & $\mathbf{I} \cdot \mathbf{I}$ & $3 \cdot 2$ & $I \cdot 0$ & $1 \cdot 3$ & $25 \cdot 0$ & $2 \cdot 9$ & $2 \cdot 2$ & 0.8 & $I \cdot 5$ & $2 \cdot 0$ & $I \cdot 0$ \\
\hline $5 \mu$ & $6 \cdot 7$ & $35 \cdot 0$ & $4 \cdot 3$ & $\mathbf{I} \cdot \mathbf{2}$ & $12 \cdot 7$ & $31 \cdot 0$ & $9 \cdot 3$ & 4.4 & $6 \cdot 3$ & $2 \cdot 2$ & $4 \cdot 3$ \\
\hline $2.5^{\mu}$ & $46 \cdot 0$ & $48 \cdot 5$ & $54 \cdot 0$ & $2 \mathrm{I} \cdot 5$ & $6 \cdot 3$ & $53 \cdot 0$ & $20 \cdot 5$ & $44 \cdot 0$ & $43 \cdot 0$ & $26 \cdot 5$ & 54.0 \\
\hline$<2.5 \mu$ & $44 \cdot 0$ & 13.5 & $39 \cdot 5$ & $74 \cdot 5$ & 0.2 & 12.9 & $67 \cdot 0$ & $50 \cdot 0$ & $48 \cdot 5$ & $68 \cdot 0$ & 39.5 \\
\hline $\begin{array}{l}\text { Lethal CT product } \mu \mathrm{g} . / 1 . \mathrm{hr} \\
\text { (paraquat-rats) }\end{array}$ & $6 \cdot 0$ & $4 \cdot 0$ & $5 \cdot 5$ & $5 \cdot 5$ & $25 \cdot 0$ & & & & & & $6 \cdot 0$ \\
\hline
\end{tabular}


A

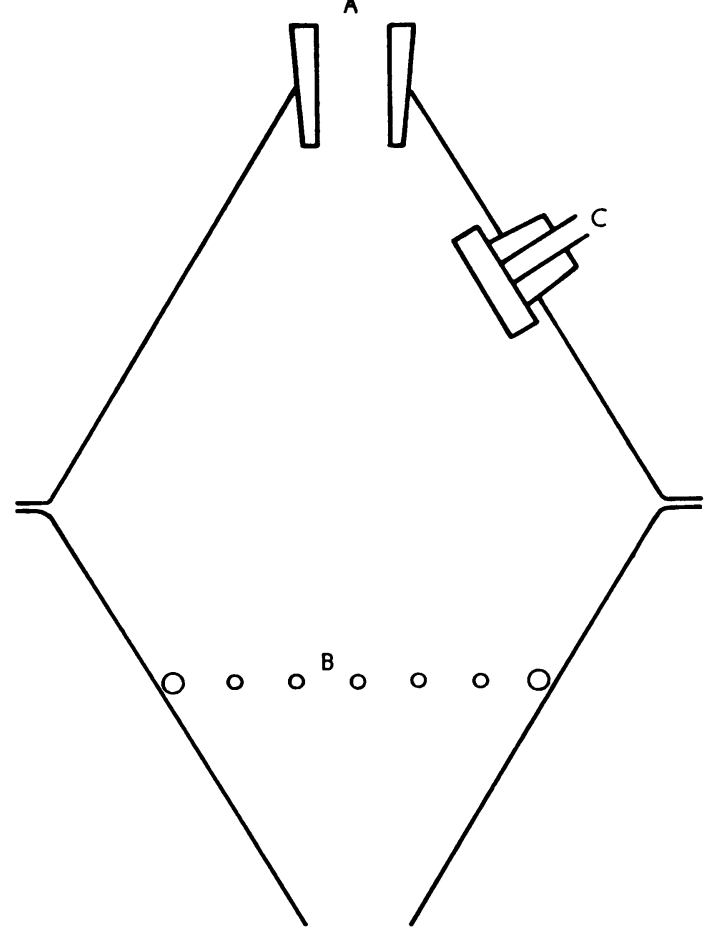

FIG. 3. Small exposure chamber. A, inlet for atomizer; B, grid; C, sampling head.

Animals did not receive food and water while in the exposure chamber. When on repeated exposure, animals were removed from the chamber at the end of the daily exposure period. These experiments were based on a five-day week, with no exposures at week-ends.

Analysis of Lungs Paraquat was determined in the lungs by the method of Daniel and Gage (1966). A $20 \%$ homogenate of the lungs was prepared in $5 \% \mathrm{w} / \mathrm{v}$ aqueous trichloroacetic acid. The supernatant layer after centrifugation was neutralized with sodium carbonate and then applied to a $0.5 \mathrm{ml}$. column of Dow ion-exchange resin AG-5oW-X8. The column was washed with water and then eluted with ro $\mathrm{ml}$. $5 \mathrm{M}$ ammonium chloride; $2 \mathrm{ml} .0 \cdot 2 \% \mathrm{w} / \mathrm{v}$ sodium dithionite in $\mathrm{N}-\mathrm{NaOH}$ was added, and the optical density was measured at $600 \mathrm{~m} \mu$ in $4-\mathrm{cm}$. cells. Recovery of known amounts of paraquat added to normal lung tissue was better than $90 \%$.

\section{Results}

\section{Single Exposures}

Paraquat The mortality from the exposures of groups of four male and four female rats to a range of paraquat aerosol concentrations for a single 6-hr. period is shown in Table II (Expt. I). The rats were apparently unaffected during the exposures, apart from a slight lethargy towards the end of the period at the higher concentrations. The condition of the rats which subsequently succumbed to the exposure progressively deteriorated; they showed piloerection and were pale and cold to the touch. Respiration became rapid and shallow and terminally laboured. Males appeared to be rather more affected than females, and tended to die earlier. These results suggest that the concentration for $50 \%$ mortality after a $6-\mathrm{hr}$ exposure was about I $\circ \mu$ g. /litre.

Post-mortem examination of the survivors after exposure to a concentration of $4.8 \mu \mathrm{g}$. $/ 1$. or more showed congested lungs with occasional petechial haemorrhages; the kidneys were pale with some

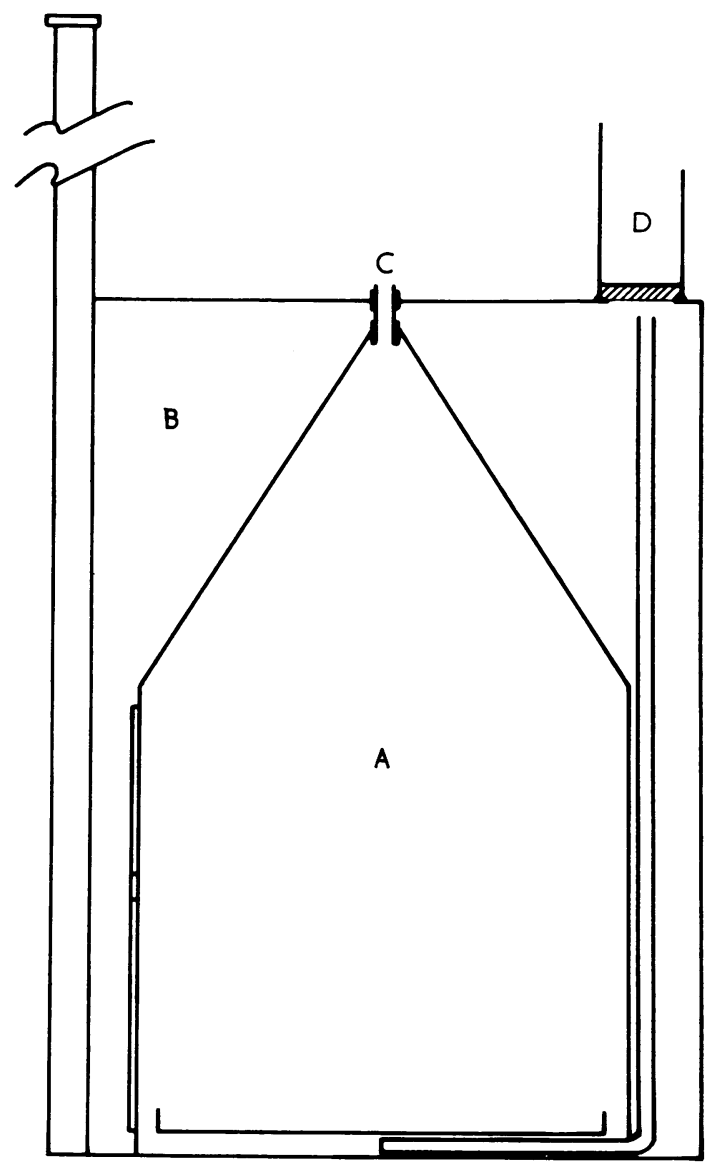

FIG. 4. Large exposure chamber. A, inner chamber; B, outer casing; $C$, inlet for atomizer; $D$, exhaust duct. 
TABLE II

Mortality in Rats AfTER a Single 6-HR. Exposure (EXPT. I)

\begin{tabular}{|c|c|}
\hline $\begin{array}{c}\text { Paraquat } \\
\text { Concentration } \\
(\mu g . / l .)\end{array}$ & Mortality \\
\hline $\begin{array}{l}32 \cdot 5 \\
13 \cdot 7 \\
4 \cdot 8 \\
2 \cdot 6 \\
1 \cdot 5 \\
1 \cdot 3 \\
0 \cdot 75 \\
0 \cdot 4\end{array}$ & 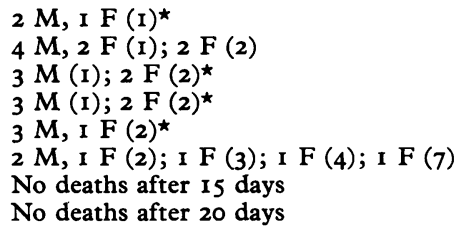 \\
\hline
\end{tabular}

Four male and four female rats at each concentration.

Numbers in parentheses indicate period in days between exposure and death. Asterisk indicates that survivors were in poor condition and were killed for autopsy. discoloured areas. Histopathological examinatior of the lungs from these animals revealed a chemica pneumonitis (Fig. 5), i.e., congestion with areas 0 oedema both diffuse and also located round the bronchi and vessels. There was an increase in the number of polymorphs and histiocytes, which wert prominent round the bronchi and vessels. Sligh cloudy swelling was seen in the kidneys anc adrenals, though this was probably not a direc effect of paraquat; the intestines, liver, testes thymus, and spleen appeared to be normal.

The results obtained by exposing rats for period: shorter than $6 \mathrm{hrs}$. are shown in Table III. Ir Expt. 2, single male rats were used in the chambes shown in Figure 3. Expt. 3 was undertaken tc obtain an estimate both of mortality and of the retention of paraquat in the lungs; groups of eigh rats were exposed and at the end of the exposur period four rats were killed for lung analysis and the other four were retained in order to record mortality

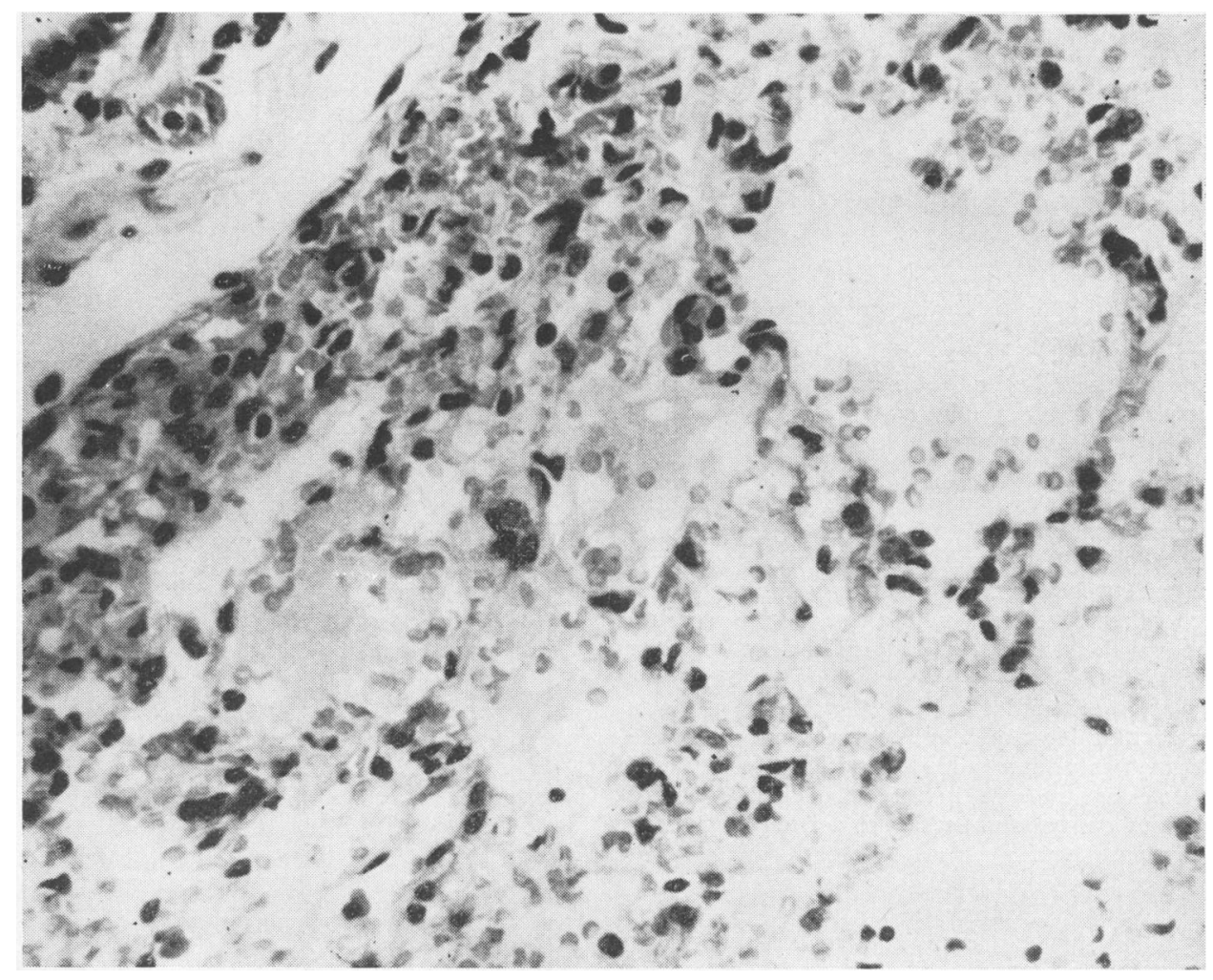

FIG. 5. Rat lung after $6 \mathrm{hr}$. inhalation of paraquat at $32.5 \mu \mathrm{g}$./litre. The section shows peribronchiolar oedema in the top left-hand corner, and alveolar oedema and haemorrhage centrally. The interalveolar tissues are congested but cellular infiltrate is minimal. H. \& E. $\times$ I,000. 
TABLE III

Mortality and Lung Retention in Rats from a Single Short Exposure

\begin{tabular}{|c|c|c|c|c|c|c|}
\hline Experiment & $\begin{array}{c}\text { Paraquat } \\
\text { Concentration } \\
(\mu g . / l .)\end{array}$ & Time (hr.) & $\begin{array}{c}\text { Concentration } \\
\times \text { Time }\end{array}$ & Mortality & \multicolumn{2}{|c|}{$\begin{array}{l}\text { Paraquat } \\
\text { in Lungs } \\
(\mu g . / r a t)\end{array}$} \\
\hline 2 & $\begin{array}{l}13.8 \\
19.4 \\
14.5 \\
14.3 \\
13.1 \\
15.6 \\
13.6 \\
13.6\end{array}$ & $\begin{array}{l}0.36 \\
0.25 \\
0.28 \\
0.25 \\
0.25 \\
0.19 \\
0.15 \\
0.075\end{array}$ & $\begin{array}{l}5 \cdot 0 \\
4 \cdot 8 \\
4 \cdot 0 \\
3 \cdot 6 \\
3 \cdot 3 \\
3 \cdot 0 \\
2 \cdot 0 \\
1 \cdot 0\end{array}$ & $\begin{array}{l}(2) \\
(3) \\
(3) \\
- \\
- \\
- \\
-\end{array}$ & & \\
\hline 3 & $\begin{array}{l}3 \cdot 1 \\
3 \cdot 05 \\
2 \cdot 8 \\
2 \cdot 25 \\
3 \cdot 3 \\
2 \cdot 77 \\
2 \cdot 4 \\
1 \cdot 9 \\
2 \cdot 2 \\
1 \cdot 2 \\
3 \cdot 1 \\
2 \cdot 1 \\
1 \cdot 0 \\
1 \cdot 1 \\
1 \cdot 1\end{array}$ & $\begin{array}{l}3 \cdot 0 \\
3 \cdot 0 \\
2 \cdot 5 \\
3 \cdot 0 \\
2 \cdot 0 \\
2 \cdot 0 \\
2 \cdot 0 \\
2 \cdot 5 \\
2 \cdot 0 \\
3 \cdot 0 \\
1 \cdot 0 \\
1 \cdot 0 \\
2 \cdot 0 \\
1 \cdot 0 \\
1 \cdot 0\end{array}$ & $\begin{array}{l}9 \cdot 3 \\
9 \cdot 1 \\
7 \cdot 0 \\
6 \cdot 7 \\
6 \cdot 6 \\
5 \cdot 5 \\
4 \cdot 8 \\
4 \cdot 7 \\
4 \cdot 4 \\
3 \cdot 6 \\
3 \cdot 1 \\
2 \cdot 1 \\
2 \cdot 0 \\
1 \cdot 1 \\
1 \cdot 1\end{array}$ & $\begin{array}{cc}4 & (2) \\
4 & (2) \\
4 & (3) \\
4 & (2) \\
4 & (3) \\
4 & (3) \\
- \\
- \\
- \\
- \\
- \\
- \\
-\end{array}$ & 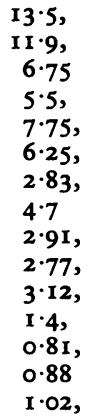 & $\begin{array}{l}11 \cdot 5 \\
10 \cdot 1 \\
\\
5.65 \\
8 \cdot 15 \\
6 \cdot 85 \\
4.35 \\
\\
3 \cdot 27 \\
3.6 \\
3 \cdot 28 \\
2.52 \\
I \cdot 84 \\
I \cdot 12\end{array}$ \\
\hline
\end{tabular}

Expt. 2: One male rat exposed in each test.

Expt. 3: Eight male rats exposed in each test; two pairs taken at the end of each exposure for duplicate paraquat determinations in the lungs.

Numbers in parentheses indicate period in days between exposure and death.

Table III indicates that when the time of exposure is varied at constant aerosol concentration and when the concentration is varied at constant time, death occurred when the product of the concentration ( $\mu \mathrm{g} . / 1$.$) and time (hr) was approximately 4$ in Expt. 2 and 5.5 in Expt. 3. As in Expt. I, the rats showed no signs of any toxic effects during and immediately after the exposure, and the rats which subsequently survived usually remained in good condition.

In order to study the effect of paraquat aerosols on a variety of species, cages containing rats, mice, guinea-pigs, and rabbits were stacked into the chamber shown in Fig. 4, which was fitted with the atomizer shown in Fig. 2b (Expt. 4). In two subsequent tests a single dog was housed in the same chamber. The results of these experiments are shown in Table IV. It is interesting that female mice and rabbits survived concentrations which were lethal to rats and guinea-pigs of both sexes. It also appeared that the male and female dog could tolerate, unharmed, exposures which were lethal to rats.

For the investigation of the effects of coarser particles, groups of eight rats were exposed in the chamber shown in Fig. 4 fitted with the atomizer shown in Fig. I (Expt. 5). The particle size range produced in this experiment is shown in Table I. Groups of eight rats were used and four of these were killed at the end of each exposure period for the analytical determination of residual paraquat in the lungs. The mortalities observed in the remaining groups of four rats are shown in Table V. All rats, including those which survived, developed reddish crusts round the eyes.

Diquat A male rat was exposed to a concentration of $23 \mu \mathrm{g}$. $/ 1$. for $15 \mathrm{~min}$.; no toxic effects were observed (Expt. 6). The experiment was repeated on another male rat, increasing the exposure time to $30 \mathrm{~min}$., and again there were no signs of toxic effects. The rats remained in good condition after the exposure.

\section{Repeated Exposures}

Paraquat A group of four male and four female rats were exposed to $0.75 \mu \mathrm{g}$./1. paraquat aerosol 
TABLE IV

Exposure of Various Species for Single Periods (Paraquat-Expt. 4)

\begin{tabular}{|c|c|c|c|c|c|c|c|}
\hline \multicolumn{4}{|c|}{ Species } & \multirow{2}{*}{$\begin{array}{l}\text { No. and Sex } \\
\qquad \begin{array}{ll}4 & \mathrm{M} \\
4 & \mathrm{~F} \\
5 & \mathrm{M} \\
5 & \mathrm{~F} \\
4 & \mathrm{M} \\
4 & \mathrm{~F} \\
2 & \mathrm{~F}\end{array}\end{array}$} & \multirow{2}{*}{$\begin{array}{c}\begin{array}{c}\text { Paraquat } \\
\text { Concentration } \\
(\mu g . / l .)\end{array} \\
\\
2 \cdot 2\end{array}$} & \multirow{2}{*}{$\begin{array}{c}\text { Time (hr.) } \\
\\
2.5\end{array}$} & Mortality \\
\hline $\begin{array}{l}\text { Rats } \\
\text { Mice } \\
\text { Guinea-pig } \\
\text { Rabbits } \\
\text { Dogs }\end{array}$ & $\begin{array}{l}\ldots \\
\ldots \\
\text { igs }\end{array}$ & $\begin{array}{l}\cdots \\
\cdots \\
\cdots \\
\cdots \\
\cdots\end{array}$ & $\begin{array}{l}\cdots \\
\cdots \\
\cdots \\
\cdots \\
\cdots\end{array}$ & & & & 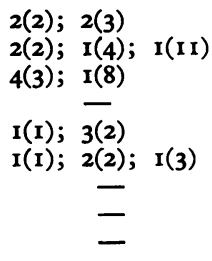 \\
\hline
\end{tabular}

Numbers in parentheses indicate period in days between exposure and death.

TABLE V

Exposure of Rats to Coarse Aerosols (Paraquat-Expt. 5)

\begin{tabular}{|c|c|c|c|c|}
\hline $\begin{array}{c}\text { Paraquat } \\
\text { Concentration } \\
(\mu g . / l .)\end{array}$ & Time (hr) & $\begin{array}{c}\text { Concentration } \\
\times \text { Time }\end{array}$ & $\begin{array}{c}\text { Paraquat } \\
\text { in Lungs } \\
(\mu g . / \text { rat })\end{array}$ & Mortality \\
\hline $\begin{array}{l}8 \cdot 2 \\
8 \cdot 8 \\
9 \cdot 8 \\
9 \cdot 0 \\
9 \cdot 6\end{array}$ & $\begin{array}{l}4.45 \\
3 \cdot 25 \\
2 \cdot 00 \\
1 \cdot 10 \\
0.52\end{array}$ & $\begin{array}{r}40 \\
30 \\
20 \\
10 \\
5\end{array}$ & $\begin{array}{rr}15 \cdot 1, & 15 \cdot 5 \\
7 \cdot 3, & 8 \cdot 9 \\
8 \cdot 8, & 9 \cdot 2 \\
4 \cdot 1, & 5 \cdot 6 \\
4 \cdot 6, & 5 \cdot 4\end{array}$ & $\begin{array}{lll}2(2) ; & \mathbf{I}(4) ; & \mathbf{I}(9) \\
3(3) ; & \mathbf{I}(5) ; & \\
\mathbf{I}(3) ; & \mathbf{I}(6) ; & \mathbf{I}(8) \\
& - & \\
& - & \end{array}$ \\
\hline
\end{tabular}

Eight male rats taken for each test. Two pairs killed immediately after exposure for duplicate lung analyses. Numbers in parentheses indicate period in days between exposure and death.

for four daily 6-hr. periods (Expt. 7). The rats showed rapid shallow breathing after the second day and two males and three females died on the day after the exposure was terminated. Two more males died on the following day, and a female rat died five days after the exposure.

Another group of four male and four female rats was exposed to $0.4 \mu \mathrm{g}$. $/ 1$. for 15 daily 6 -hr. periods spread over three weeks. No effects were observed during the first three days of exposure, but as the experiment proceeded the rats developed intermittent noisy breathing and appeared pale. Growth was normal in the males but in the females it was rather irregular. All rats survived the exposures, and a haematological examination for haemoglobin, packed cell volume, red, white, and differential cell blood count, and platelet count at the end of the experiment showed no abnormalities. The urine gave a negative reaction for reducing sugars, bilirubin, and blood, and the protein content was within normal limits. The animals were killed; the post-mortem appearance of the organs was normal and their weights were within normal limits. A histopathological examination of the lungs showed marginal changes which may have been due to the exposure to paraquat, but this was difficult to assess as a group of control rats maintained under similar conditions but without exposure to paraquat showed signs of mild lung infection. No pathological changes were observed in the liver, kidneys, thymus, adrenals, intestine, pancreas, and spleen.

A group of four male and four female rats exposed to $0.1 \mu \mathrm{g}$./1. for 15 daily $6-\mathrm{hr}$. periods showed no toxic signs which could be attributed to the aerosol. The lungs appeared normal at histopathological examination.

Another group of four male and four female rats were exposed to an average concentration of $0.65 \mu \mathrm{g} . / 1$. for 15 daily $\mathrm{I}-\mathrm{hr}$. periods, which represented a daily concentration-time product similar to that in the previous test. The rats grew normally and remained in good condition, but at post-mortem examination the lungs appeared congested. A microscopical examination of lung tissue revealed areas of consolidation with some haemorrhage.

No signs of lung or nose irritation were observed 
when a group of four male and four female rats were exposed to $0.06 \mu \mathrm{g}$. $/ 1$. for 15 daily $6-\mathrm{hr}$. periods.

In order to study the effect of a more prolonged exposure to a low concentration, a group of four male and four female rats was exposed to an average concentration of $0.003 \mu \mathrm{g}$. $/ 1 ., 6 \mathrm{hr}$. a day, 5 days a week, for 2 months. The rats grew normally and remained in good condition. The organs appeared normal at post-mortem examination, and no pathological changes were observed on microscopical examination of lung tissue.

A group of 24 male rats was exposed to an average concentration of $0.65 \mu \mathrm{g}$. $/ 1$. for five daily I-hr. periods (Expt. 8). Each day a few rats were removed and the lungs were removed for paraquat determination; the results are presented in Table VI. The

TABLE VI

Accumulation of Paraguat in Rat Lungs on REPEATED EXPOSURE (EXPT. 8)

\begin{tabular}{c|c|c}
\hline Day & $\begin{array}{c}\text { No. of Lungs } \\
\text { for Analysis }\end{array}$ & $\begin{array}{c}\text { Paraquat Content } \\
\text { in Lungs } \\
(\mu \mathrm{gg} / \text { rat })\end{array}$ \\
\hline I & 4 & $0 \cdot 92$ \\
2 & 4 & $1 \cdot 58$ \\
3 & 3 & $1 \cdot 62$ \\
4 & 3 & $2 \cdot 30$ \\
5 & 2 & $2 \cdot 88$ \\
\hline
\end{tabular}

Rats exposed for five daily one-hr. periods to $0.65 \mu \mathrm{g} . / 1$ paraquat.

rats were unaffected by this exposure and the lungs appeared normal. Six animals retained after the exposure period remained in good condition.

Diquat A group of four male and four female rats was exposed to a concentration of $2 \mu \mathrm{g}$. $/ 1$. diquat for 15 daily 6-hr. periods (Expt. 9). The males remained in good condition throughout the experiment, but in the females breathing was a little noisy during the early stages of the experiment and subsequently returned to normal. With both sexes weight gain was a little below normal.

Another group of four male and four female rats was exposed to $0.5 \mu \mathrm{g}$. $/ \mathrm{l}$. diquat aerosol for 15 daily 6-hr. periods. Both sexes remained in good condition and growth was within normal limits.

A haematological examination on both the experimental groups revealed no abnormalities, and the post-exposure clotting tests and blood urea concentrations were within the limits of the colony. An examination of urine showed values for $p \mathrm{H}$, specific gravity, and protein within the normal range, and tests for glucose and bilirubin were negative. At post-mortem examination the organ weights were within normal limits, and the organs appeared normal with the exception of the lungs at the higher concentration, which were somewhat congested. A histopathological examination of the lungs at the higher concentration showed signs of irritation, with peribronchial lymphoid hyperplasia, slight perivascular oedema, and an excess of macrophages in the alveoli. All other tissues appeared normal.

The following species were exposed to an average concentration of $\mathrm{I} \cdot 06 \mu \mathrm{g}$./1. for I5 daily 6-hr. periods (Expt. 10): four male and four female rats, five male and five female mice, four male and four female guinea-pigs, two female rabbits and a male beagle.

All animals remained in good condition during the exposure, apart from the rabbits which showed rapid, shallow breathing, but these recovered at the end of the experiment. There was no deterioration in condition in any of the animals after the exposure.

Paraquat Retention by the Rat Lung In Expt. 3 (Table III), four rats were killed immediately after exposure to a range of paraquat aerosol concentrations for varying times and the lungs were removed. Duplicate determinations of the paraquat contents were made, taking the lungs from a pair of rats for each. Lung analyses were similarly made on the rats exposed to the coarser aerosol in Expt. 5 (Table V). The progressive accumulation of paraquat in the lungs after repeated exposure is shown in Table VI (Expt. 8).

Clearance of Paraquat from the Rat Lung Two groups of 16 rats were given single exposures to paraquat aerosols (Expt. I I). A pair of rats was taken from these groups at intervals after exposure and killed for lung analysis. The results obtained are shown in Table VII.

\section{Discussion}

Paraquat It is evident from these experiments that paraquat aerosols can cause severe lung damage when inhaled. The attack appears to be on the alveolar membranes, leading to oedema and haemorrhage, and it is in line with the previously observed action of paraquat on the mucous lining of the gut and pharynx and with the high toxicity by intratracheal injection. After single exposures to lethal concentrations, death is usually delayed for several days, and during this period the condition of the animal progressively deteriorates. At concentrations only a little below the lethal figure, 
TABLE VII

Clearance of Paraquat from Lungs after Exposure (Expt. i i)

\begin{tabular}{|c|c|c|c|c|c|c|c|}
\hline \multirow{2}{*}{$\begin{array}{c}\text { Paraquat } \\
\text { Concentration } \\
(\mu g . / l .)\end{array}$} & \multirow{2}{*}{$\begin{array}{c}\text { Exposure } \\
\text { Time } \\
\text { (hr.) }\end{array}$} & \multirow{2}{*}{ Mortality } & \multicolumn{5}{|c|}{ Paraquat in Lung ( $\mu g . /$ rat) } \\
\hline & & & $\begin{array}{c}o \\
h r .\end{array}$ & $\begin{array}{l}18 \\
h r\end{array}$ & $\begin{array}{l}24 \\
h r\end{array}$ & $\begin{array}{l}48 \\
h r\end{array}$ & $\begin{array}{l}66 \\
h r .\end{array}$ \\
\hline $\begin{array}{l}3 \cdot 0 \\
1 \cdot 9\end{array}$ & $\begin{array}{l}2 \cdot 0 \\
2 \cdot 5\end{array}$ & $3(2) ;{ }^{2(3)}$ & $\begin{array}{l}5.65 \\
4.7\end{array}$ & $\begin{array}{l}3.7 \\
2.85\end{array}$ & $\overline{2 \cdot 75}$ & $\begin{array}{l}0.75 \\
1.58\end{array}$ & $\begin{array}{l}0.32 \\
0.91\end{array}$ \\
\hline
\end{tabular}

Sixteen male rats exposed as indicated. Two rats taken at intervals for paraquat in lung determinations. Figures in parentheses indicate period in days between exposure and death.

the rats show little sign of lung irritation and, in general, rats which show any marked effects will eventually succumb. Microscopical examination of the lungs from affected animals does not reveal the tissue proliferation which has been reported after the systemic absorption of large doses of paraquat (Clark et al., I966).

The intensity of the toxic action is a function of the concentration, of the duration of exposure, and of the particle size distribution. The results in Tables II to V show that the mortality in rats after single exposures is determined by the product of the concentration and the time of exposure, and the higher this product is, the shorter the delay between exposure and death. Death does not occur until this CT product has exceeded a threshold value. The magnitude of the threshold value varies somewhat in the different experiments, and Table I shows that this lethal CT product is a rather complex function of particle size. In man, it is considered that particles in the region of I $\mu$ diameter make the greatest contribution to the toxicity of an inhaled aerosol (Hatch and Gross, 1964). In Expt. 2 (Table I) the proportion of particles less than $2.5 \mu$ is relatively low, yet the toxicity appears to be higher than in other experiments with a greater proportion in this range. Moreover, although the toxicity of the relatively coarse aerosol in Expt. 5 is much lower, it is higher than might be expected from the measured size distribution. At least $80 \%$ of this aerosol is Io $\mu$ or greater and might therefore be expected to be retained in the nose, while the proportion less than $2.5 \mu$ is negligible. An inspection of Table I suggests that the most lethal particles for the rat are in the region of $3 \mu$ and that particles both smaller and larger than this are less toxic. This observation, which is in contradiction to an observation in the literature that the retention of particles by man and by experimental animals is very similar (Palm, McNerney, and Hatch, 1956), probably derives from a difference in the relation between length and diameter of the air passages and the respiratory minute volume in the two species It is possible that in the rat the smaller particles which reach the alveolar regions do not reside there long enough to be deposited by sedimentation before they are exhaled, and the particle diameter for maximal retention may, therefore, be greater than in man. If this observation could be confirmed by exposing rats to monodisperse aerosols, it would be profitable to make a theoretical study of the deposition of particles in the rat lung similar to those which have been undertaken in man (Findeisen, 1935; Landahl, 1950).

The exposure of a variety of species to paraquat aerosols (Table IV) shows that the acute toxicity to guinea-pigs and male mice is similar to that observed in rats. Female mice are less affected and this sex difference has also been observed in rats but to a lesser extent. Female rabbits were unaffected at a concentration lethal to rats, and no toxic signs were observed in a dog exposed to five times the lethal CT product for rats.

The dependence of toxicity on the product of the concentration and the duration of exposure is applicable only to short exposures. The effects obtained after repeated exposure of rats to paraquat aerosols (Expt. 7) are less than would have been expected from the total exposure. No deaths were observed after repeated exposure to $0.4 \mu \mathrm{g}$. $/ 1$., and the no-effect level for repeated 6-hr. exposures was in the region of $0.1 \mu \mathrm{g}$./litre.

The influence of concentration and time on the toxicity of paraquat aerosols suggests that after short exposures paraquat is not readily absorbed through the alveolar membranes. This is confirmed by the paraquat concentration in the lungs immediately after single and repeated exposures (Tables III and VI) and by the subsequent slow clearance from the lungs (Table VII). This accords with the observation that paraquat is poorly absorbed from the gut and does not readily enter the tissues (Daniel and Gage, 1966). The total retention during exposure does not exceed about one-fifth of 
the quantity calculated to be inhaled, on the assumption that the minute respiratory volume of the rat is about $100 \mathrm{cc}$. This apparently low retention probably derives from the low deposition of finer particles, while the coarser particles are retained in the nose and do not reach the lungs.

Table III shows that the lethal CT product for a fine aerosol is associated with a lung retention of about $6 \mu \mathrm{g}$., and death will not occur if the amount of paraquat in the lungs is less than this figure. With the coarse aerosol the lung retention at death is very little higher, although the lethal CT product is at least four times greater. This is strong evidence that the coarser particles, which are trapped in the nose and upper respiratory passages, are not lethal, though they may cause local irritation. According to the results in Table VII, the half-life of paraquat in the lungs is about $36 \mathrm{hr}$, and a similar figure may be derived from the rate of accumulation of paraquat in the lungs after repeated exposure (Table VI).

Diquat The acute experiments in rats have shown that diquat is much less toxic than paraquat; no effects were produced at $23 \mu \mathrm{g}$./1. for $30 \mathrm{~min}$., which is double the exposure of paraquat found to be lethal to rats. The repeated exposure of rats has shown lung irritation at $2 \mu \mathrm{g}$./1., with no effects at $0.5 \mu \mathrm{g} . / 1$. , and this suggests that the subacute toxicity of diquat is at most one-fifth that of paraquat. This no-effect level is supported by similar experiments involving the repeated exposure of mice, guinea-pigs, and a $\operatorname{dog}$ to $1 \mu \mathrm{g}$./1., though rabbits exhibited slight signs of irritation at this level.

\section{Conclusions}

The no-effect level for a 'respirable' paraquat aerosol in the rat is about $0.1 \mu \mathrm{g}$./1. for repeated 6-hr. exposures, and although less information is available for the dog, it is probably at least five times this value in this species. It is probable that the results in the dog are more applicable to man than are those in the rat, as both the relation between minute respiratory volume and body weight and the relation between minute volume and the anatomy of the lung are more similar. These observations suggest that an average concentration of $0.1 \mathrm{mg} . / \mathrm{m}^{3}$ would not be excessive for occupational exposure to 'respirable' paraquat aerosols. With 'respirable' diquat aerosols this concentration could be raised to $0.5 \mathrm{mg} . / \mathrm{m}^{3}$

The acute experiments have given a clear indication that the effect of paraquat by inhalation is cumulative, and higher concentrations than $0.1 \mathrm{mg} . / \mathrm{m}^{3}$ could be inhaled for short periods without risk. However, as the repeated experiments have shown that a I-hr. exposure a day to $0.65 \mu \mathrm{g}$. $/ 1$. is more toxic than $6 \mathrm{hr}$. to $0.12 \mu \mathrm{g}$. $/ 1$., and that, after five days of the former exposure, the lungs have not yet reached their equilibrium content of paraquat (Table VI), it seems desirable that an upper limit of $0.5 \mathrm{mg} . / \mathrm{m}^{3}$ should be established. Similarly, the upper limit for 'respirable' diquat aerosols should be $2.0 \mathrm{mg} . / \mathrm{m}^{3}$

It is possible to ascertain the aerosol concentrations produced during the application of paraquat and diquat by the use of suitable field analytical methods. It would be difficult to make any valid generalization from the results of such tests, which are much influenced by local conditions. An alternative approach is to study the concentration of fine particles produced by agricultural spraying equipment under controlled conditions, and then to assess the probable maximal concentration likely to be inhaled when such equipment is used. Gage and Seaborn (1968) have recently carried out such an investigation with the mistblower, which is considered to produce more fine droplets than other equipment currently in use. They deduced that, with a spray solution containing $\mathrm{I} \%$ active ingredient, the concentration of that ingredient in 'respirable' particles, which was likely to be inhaled during agricultural application, would probably not exceed the limits recommended above under normal conditions.

Under exceptional conditions, for example if a man spends much of his time walking through spray drift prevented from dispersal by overhanging foliage, there may be a risk of lung damage from fine particles, and also of irritation from coarser particles trapped in the upper respiratory tract, possibly leading to nose-bleeding. In such circumstances a filter respirator should be worn. If measurements of atmospheric aerosol concentrations are required they are best obtained from a personal sampler attached to a spray operator during application. Gage and Seaborn (r968) have shown that the total weight of particles in the minor distribution from a mistblower is about four times the total weight of 'respirable' particles, and a fair estimate of the hazard could be obtained from a simple filter air sampler, provided that the filter is protected from coarse droplets. A more convenient instrument for this purpose is the Unico Selective Dust Sampler Model $2 \cdot 8$ (Unican Industrial Equipment Corporation), which employs a battery-operated pump and a small cyclone separator to remove the coarser particles, the 'respirable' particles being collected on a filter.

The above observations apply to the mistblower; 
with other types of equipment more commonly used for the application of herbicides, such as the lowpressure spray, the risk of lung damage is negligible, as the concentration of 'respirable' particles is much lower.

A report on the histopathological examination of lung tissue was prepared under the direction of Dr. D. M. Conning. Technical assistance was provided by Miss Linda Dudley, Miss Lesley Turner, Mr. C. A. Manley, and Mr. R. A. Riley.

\section{REFERENCES}

Clark, D. G., and Hurst, E. W. (1968). In preparation.

-, McElligott, T. F., and Hurst, E. W. (1966). The toxicity of paraquat. Brit. F. industr. Med., 23, 126-132.

Daniel, J. W., and Gage, J. C. (1966). Absorption and excretion of diquat and paraquat in rats. Ibid., 23, 133-136.

Findeisen, W. (1935). Ueber das Absetzen kleiner, in der Luft suspendierten Teilchen in der menschlichen Lunge bei der Atmung. Pfiugers Arch. ges. Physiol., 236, 367-369.
Gage, J. C. (1953). A controlled fluid-feed atomizer. f. sci. Instrum., 30, 25.

- (1959). The toxicity of epichlorhydrin vapour. Brit. $\mathcal{F}$. industr. Med., 16, 1 I-14.

droplets produced by a mistblower. $\mathcal{f}$. agric. Engng Res., 13, $120-126$.

Hatch, T. F., and Gross, P. (1964). Pulmonary Deposition and Retention of Aerosols. Academic Press, New York.

Landahl, H. D. (1950). On the removal of air-borne droplets by the human respiratory tract. I. The lung. Bull. Math. Biophys., 12, 43-56.

Lippmann, M. (I96I). A compact cascade impactor for field survey sampling. Amer. industr. Hyg. Ass. F., 22, 348-353.

Meloche, C. C., and Fredrick, W. G. (1932). A lubricant insoluble in organic solvents. F. Amer. chem. Soc., 54, 3264-3266.

Morrow, P. E. (1964). Evaluation of inhalation hazards based upon the respirable dust concept and the philosophy and application of selective sampling. Amer. industr. Hyg. Ass. F., 25, 213-236.

Palm, P. E., McNerney, J. M., and Hatch, T. (1956). Respiratory dust retention in small animals. Arch. industr. Hlth, 13, 355-365.

\section{The July (1968) Issue}

Chronic Respiratory Disease in Mining Communities in Marion County, West Virginia I. T. T. Higgins, M. W. Higgins, M. D. Lockshin, and N. CANALE

Byssinosis, Chronic Bronchitis, and Ventilatory Capacities in Workers Exposed to Soft Hemp Dust F. Valić, E. ŽUuškin, Joan Walford, W. Keršrić, and R. Pauković

The Newcastle Papers in Industrial Medicine over the Last 21 Years R. C. Browne

Nephropathy in Chronic Lead Poisoning Ruth Lilis, N. Gavrilescu, B. Nestorescu, C. Dumitriu, and ANa Roventa

Distribution and Excretion of Triethyllead in Rats WANDA BolanOwSKA

Determination of Lead in Blood by Atomic Absorption Spectrophotometry Stig Selander and KIM CRAMER

A Method for Determination of Trichloroethanol and Trichloroacetic Acid in Urine SHIRO TANAKA and MASAYUKI IKEDA

Carbon Disulphide Poisoning with Increased Ethereal Sulphate Excretion L. S. DJERASSI and R. LuMBRoso

Effect of Microwaves at X-band on Guinea-pig Skin in Tissue Culture I. Microwave Apparatus for Exposing Tissue and the Effect of the Radiation on Skin Respiration J. C. LAWRENCE

Effect of Microwaves at X-band on Guinea-pig Skin inTissue Culture 2. Effect of the Radiation on Skin Biochemistry ShIRLEY A. CARNEY, J. C. LAWReNCE, and C. R. Ricketts

A Field Assessment of a Prototype Meter for Measuring the Wet-bulb Globe-thermometer Index J. D. WALTERS

Notes and Miscellanea

The Plasma Content and Excretion of Catecholamines in Nitroglycerine Workers J. HÄGGENDAL, G. JoHNSSON, and R. P. LUND

Skin Absorption of Toluene, Styrene, and Xylene by Man TADeusz Dutkiewicz and HaLina Tyras Influenza Vaccine and Long-term Protection P. B. Cook

\section{Book Reviews}

A number of copies are still available and may be obtained from the Publishing Manager, British Medical Association, Tavistock Square, London W.C.I, price I8s. $6 d$. 